\title{
Evaluation and Identification of Promising Bivoltine Double Hybrids of the Silkworm Bombyx mori L. for Tropics Through Large Scale In-House Testing
}

\author{
Dayananda*, Satish Kulkarni, Pala Rama Mohana Rao, Obalaiah Gopinath, and Sundara Murthy Nirmal \\ Kumar \\ Central Sericultural Research and Training Institute (CSRTI), Mysore 570 - 008, India
}

(Received 11 August 2011; Accepted 22 November 2011)

An attempt was made to assess the potentiality of bivoltine double hybrids under simulated conditions of farmers to identify the suitable bivoltine double hybrid combination. Four bivoltine double hybrids developed at Central Sericultural Research and Training Institute (CSRTI), Mysore along with popular single hybrid, CSR2 x CSR4 as control was assessed for economic traits. The rearing results showed significant improvement of $\mathbf{2 0 - 2 4 \%}$ in fecundity of the double hybrids studied over single hybrid. Among the double hybrids, $[\mathrm{D} 7 \times \mathrm{S5}] \times[\mathrm{D13} \times \mathrm{S1}]$ recorded significantly higher survival $(89.58 \%)$, cocoon yield $(76.328 \mathrm{~kg} /$ 50,000 eggs), cocoon price (Rs. $180.87 / \mathrm{kg}$ ) and lower cocoon leaf ratio of $1: 21.80$. The performance of the reeling traits were also found significantly superior in $[\mathrm{D} 7 \times \mathrm{S5}] \times[\mathrm{D13} \times \mathrm{S1}]$ with higher filament length $(1100 \mathrm{~m})$, reelability $(88 \%)$, raw silk $(18.55 \%)$ and neatness (92 points) compared to CSR2 $\times$ CSR4 and other double hybrids evaluated. Besides, the cocoons of $[D 7 \times$ S5 $] \times[D 13 \times$ S1 $]$ exhibit uniformity in size with a standard deviation of $<8$. Overall data indicated the superiority of $[D 7 \times$ S5 $] \times[D 13 \times$ S1 $]$ compared to the other hybrids evaluated and it has profound influence in expressing the full potentiality in the field.

Key words: Bivoltine Double Hybrids, Bombyx mori L., Cocoon Uniformity, Economic Traits

\footnotetext{
*To whom the correspondence addressed

Silkworm Breeding Laboratory, Central Sericultural Research and Training Institute, Central Silk Board, Govt. of India, Srirampura, Mysore 570-008, India.

Tel :+91-821-236-2757; Fax: +91-821-236-2845

E-mail: dayananda1966@yahoo.co.in
}

\section{Introduction}

Mulberry silkworm, Bombyx mori L. is an important economic insect, which is commercially exploited for silk. Silkworm breed/hybrid is the prime requirement for ultimate growth of sericulture industry. Prior to 1970s the Indian sericulture had been characterized by poor productivity and poor quality (Krishnaswamy, 1990). To overcome these twin defects serious researches were undertaken at Central Sericultural Research and Training Institute (CSRTI), a premier research Institute in India by evolving many bivoltine silkworm hybrids. Many productive bivoltine hybrids which produce international gradable silk have been developed for rearing during favorable seasons (Basavaraja et al., 1995). But whenever, there is an improvement in quantitative character in parental breed, the egg laying capacity by the individual mother moth and survival of larvae are significantly affected. Although, the survival is comparatively more than the parents in single hybrids, the egg number remains low. With increase in demand for F1 silkworm hybrids including bivoltine hybrids, the double cross hybrids could be popularized in India due to its obvious advantages like easy rearing of foundation crosses, withstanding fluctuating environmental conditions, showing superiority to parental breeds in growth, vigor and other economic characters besides cocoon yield, which is on par with the single hybrids (Nirmal Kumar et al., 1998). It is also established that, rearing inbred lines to be utilized as parents for the production of F1 hybrids is handicapped by lower fecundity and difficulty in rearing (Nagaraju et al., 1996). If, the mother moth is a hybrid, the number of eggs laid could be increased. Keeping in view of the demand for double hybrids to the industry an attempt has been made by CSRTI led to development of many bivoltine 
Table 1. Mean values of rearing performance of bivoltine double hybrids under large scale in-house testing

\begin{tabular}{cccccccc}
\hline $\begin{array}{c}\text { Hybrid } \\
\text { combination }\end{array}$ & $\begin{array}{c}\text { Fecu- } \\
\text {-ndity } \\
(\mathrm{No} .)\end{array}$ & $\begin{array}{c}\text { Hatc- } \\
\text {-hing } \\
(\%)\end{array}$ & $\begin{array}{c}\text { Weight of } \\
\text { matured larva } \\
(\mathrm{g})\end{array}$ & $\begin{array}{c}\text { Survival } \\
(\%)\end{array}$ & $\begin{array}{c}\text { Cocoon yield/ } \\
50000 \text { eggs } \\
(\mathrm{kg})\end{array}$ & $\begin{array}{c}\text { Leaf cocoon } \\
\text { ratio }\end{array}$ & $\begin{array}{c}\text { Rate/ kg of } \\
\text { cocoon }(\mathrm{Rs} .)\end{array}$ \\
\hline $\begin{array}{c}{[\mathrm{D} 2 \times \mathrm{S} 8] \times} \\
{[\mathrm{S} 1 \times \mathrm{D} 15]}\end{array}$ & 603 & 94.96 & 4.889 & 87.33 & 68.798 & 24.50 & 161.67 \\
\hline $\begin{array}{c}{[\mathrm{D} 1 \times \mathrm{D} 2] \times} \\
{[\mathrm{D} 13 \times \mathrm{D} 11]}\end{array}$ & 605 & 94.44 & 4.608 & 79.89 & 66.074 & 23.00 & 157.43 \\
\hline $\begin{array}{c}{[\mathrm{D} 7 \times \mathrm{S} 5] \times} \\
{[\mathrm{D} 13 \times \mathrm{S} 1]}\end{array}$ & 623 & 95.73 & 5.152 & 89.58 & 76.328 & 21.80 & 180.87 \\
\hline $\begin{array}{c}{[\mathrm{CSR} 2 \times \mathrm{CSR} 27] \times} \\
{[\mathrm{CSR} 6 \times \mathrm{CSR} 26]}\end{array}$ & 613 & 96.32 & 4.829 & 84.59 & 71.009 & 22.60 & 163.13 \\
\hline $\mathrm{CSR} 2 \times \mathrm{CSR} 4$ & 502 & 95.42 & 4.781 & 83.00 & 71.698 & 22.50 & 161.33 \\
\hline $\mathrm{CD}$ at 5\% & $21.62^{2)}$ & 1.75 & $0.30^{1)}$ & $5.84^{1)}$ & $4.25^{1)}$ & $0.70^{2)}$ & $7.75^{2)}$ \\
\hline SE \pm & 7.01 & 0.57 & 0.09 & 1.89 & 2.68 & 0.23 & 2.52 \\
\hline
\end{tabular}

1) Significant differences at $5 \%$ level

2) Significant differences at $1 \%$ level

double hybrid combinations (Mal Reddy et al., 2003; Suresh Kumar et al., 2010). Though the double hybrids are known for their productive merit and capable to produce 2-3A grade silk of international standard, selection of potential hybrid combination to serve as commercial exploitation material is one of the pre-requisites contributing to the success of hybrids under the given environment. Proper evaluation of silkworm hybrids in the in-house under large scale by providing simulated conditions of farmers help to critically analyze the most effective hybrid combination before choosing for commercial exploitation (Dayananda, 2010) . In this background, the present investigation has been undertaken to identify the suitable bivoltine double hybrid for commercialization.

\section{Materials and methods}

The four robust/productive bivoltine double hybrids of silkworm Bombyx mori L. developed at CSRTI, Mysore viz., $[\mathrm{D} 2 \times \mathrm{S} 8] \times[\mathrm{S} 1 \times \mathrm{D} 15], \quad[\mathrm{D} 1 \times \mathrm{D} 2] \times[\mathrm{D} 13 \times \mathrm{D} 11]$, $[\mathrm{D} 7 \times \mathrm{S} 5] \times[\mathrm{D} 13 \times \mathrm{S} 1],[\mathrm{CSR} 2 \times \mathrm{CSR} 27] \times[\mathrm{CSR} 6 \times$ CSR26] along with the existing bivoltine single hybrid in the field CSR2 x CSR4, as a control were assessed under large scale in-house evaluation as per the farmers practice. These hybrids were reared thrice at CSRTI, Mysore during 2008-09 under large scale, as per simulated conditions of farmer with a minimum of 50,000 eggs per hybrid in four replications by following shoot rearing technique on V1 mulberry leaf and evaluated for their various economic traits. The cocoons were har- vested on $6^{\text {th }}$ day of mounting and assessed the following day. Samples of three $\mathrm{kg}$ cocoons from each replication were reeled on multi-end reeling machine at Silk Reeling Unit of CSRTI, Mysore for assessing the reeling parameters. To know the cocoon size variability, one hundred cocoons were randomly picked up and three cocoon size variables viz., cocoon length, cocoon width and length/width index were determined. Cocoon length and width were measured by using vernier calipers. Variability in cocoon size was determined on the basis of standard deviation and co-efficient of variation (Mano et al., 1994). Observations on various economic traits recorded from three rearing trials were pooled together and analyzed statistically by 2 way ANOVA (Singh and Chaudhary, 1977).

\section{Results}

Mean of comparative rearing and reeling performance and its statistical analysis are presented (Tables 1 and 2). The results revealed significant variation among the hybrids for most of the economic traits.

\section{Fecundity and hatching}

Perusal of the data indicated significantly $(\mathrm{p}<0.01)$ higher fecundity in all the double hybrids ranged from 603 to 623 compared to 502 in CSR $2 \times$ CSR4. No significant difference in hatching percent in the hybrids studied with the highest hatching of 96.32 recorded for [CSR2 $\times$ CSR27] $\times[$ CSR $6 \times$ CSR26] and the lowest of $94.44 \%$ recorded for $[\mathrm{D} 1 \times \mathrm{D} 2] \times[\mathrm{D} 13 \times \mathrm{D} 11]$. 
Table 2. Mean values of reeling performance of bivoltine double hybrids under large scale in-house testing

\begin{tabular}{|c|c|c|c|c|c|c|c|c|}
\hline $\begin{array}{c}\text { Hybrid } \\
\text { combination }\end{array}$ & $\begin{array}{c}\text { Cocoon } \\
\text { weight }(\mathrm{g})\end{array}$ & $\begin{array}{l}\text { Shell weight } \\
(\mathrm{g})\end{array}$ & $\begin{array}{c}\text { Shell } \\
\text { percent }\end{array}$ & $\begin{array}{l}\text { Filament } \\
\text { length }(\mathrm{m})\end{array}$ & $\begin{array}{l}\text { Denier } \\
\text { (d) }\end{array}$ & $\begin{array}{c}\text { Reela- } \\
\text {-ability (\%) }\end{array}$ & Raw silk (\%) & $\begin{array}{c}\text { Neat- } \\
-\operatorname{ness}(p)\end{array}$ \\
\hline $\begin{array}{l}{[\mathrm{D} 2 \times \mathrm{S} 8] \times} \\
{[\mathrm{S} 1 \times \mathrm{D} 15]}\end{array}$ & 1.882 & 0.428 & 22.76 & 1086 & 2.77 & 87.00 & 17.40 & 90.67 \\
\hline $\begin{array}{l}{[\mathrm{D} 1 \times \mathrm{D} 2] \times} \\
{[\mathrm{D} 13 \times \mathrm{D} 11]}\end{array}$ & 1.834 & 0.416 & 22.65 & 1009 & 2.78 & 81.48 & 16.76 & 91.33 \\
\hline $\begin{array}{l}{[\mathrm{D} 7 \times \mathrm{S} 5] \times} \\
{[\mathrm{D} 13 \times \mathrm{S} 1]}\end{array}$ & 2.002 & 0.460 & 22.96 & 1100 & 2.74 & 88.00 & 18.55 & 92.00 \\
\hline $\begin{array}{c}{[\mathrm{CSR} 2 \times \mathrm{CSR} 27] \times} \\
{[\mathrm{CSR} 6 \times \mathrm{CSR} 26]}\end{array}$ & 1.950 & 0.448 & 22.95 & 1089 & 2.63 & 86.00 & 18.20 & 90.67 \\
\hline $\mathrm{CSR} 2 \times \mathrm{CSR} 4$ & 1.837 & 0.424 & 23.07 & 970 & 2.69 & 87.00 & 17.93 & 91.00 \\
\hline $\mathrm{CD}$ at $5 \%$ & $0.11^{1)}$ & $0.03^{1)}$ & 0.56 & $41.21^{2)}$ & 0.12 & $2.96^{2)}$ & $0.60^{2)}$ & $1.00^{2)}$ \\
\hline $\mathrm{SE} \pm$ & 0.03 & 0.01 & 0.18 & 13.37 & 0.04 & 0.96 & 0.19 & 0.32 \\
\hline
\end{tabular}

1) Significant differences at 5\% level

2) Significant differences at $1 \%$ level

\section{Matured larval weight}

Larval weight showed significant differences $(\mathrm{p}<0.05)$ with highest larval weight of $5.152 \mathrm{~g}$ recorded for $[\mathrm{D} 7 \times$ $\mathrm{S} 5] \times[\mathrm{D} 13 \times \mathrm{S} 1]$ and lowest of $4.608 \mathrm{~g}$ in $[\mathrm{D} 1 \times \mathrm{D} 2] \times$ [D13 $\times$ D11].

\section{Survival and Cocoon yield}

Cocoon yield and survival showed significant differences $(p<0.05)$ with the highest values of $76.328 \mathrm{~kg} / 50,000$ eggs and $89.58 \%$, respectively and the lowest of $66.074 \mathrm{~kg}$ and $79.89 \%$ recorded for $[\mathrm{D} 1 \times \mathrm{D} 2] \times[\mathrm{D} 13 \times \mathrm{D} 11]$.

\section{Leaf cocoon ratio}

Leaf cocoon ratio (LCR) is the measure to know the quantity of leaf required in $\mathrm{kgs}$ to produce one $\mathrm{kg}$ of green cocoons. [D7 $\times \mathrm{S} 5] \times[\mathrm{D} 13 \times \mathrm{S} 1]$ recorded the significantly $(\mathrm{p}<0.01)$ lowest LCR of $21.80: 1$ and the highest $(24.50: 1)$ was recorded for $[\mathrm{D} 2 \times \mathrm{S} 8] \times[\mathrm{S} 1 \times \mathrm{D} 15]$.

\section{Rate per kg of cocoons}

There is a significant difference $(\mathrm{p}<0.01)$ with the highest cocoon price of Rs. $180.87 / \mathrm{kg}$ recorded for $[\mathrm{D} 7 \times \mathrm{S} 5] \times$ $[\mathrm{D} 13 \times \mathrm{S} 1]$ and the lowest of Rs. 157.43 recorded for [D1 $\times \mathrm{D} 2] \times[\mathrm{D} 13 \times \mathrm{D} 11]$.

\section{Cocoon traits}

The cocoon weight and cocoon shell weight of the hybrids showed significant difference $(\mathrm{p}<0.05)$ with the cocoon weight ranged from 1.834 to $2.002 \mathrm{~g}$ and cocoon shell weight ranging from 0.416 to $0.460 \mathrm{~g}$ with the highest values for both the parameters recorded for $[$ D7 $\times$ S5 $] \times[$ D13 $\times \mathrm{S} 1]$ and the lowest for $[\mathrm{D} 1 \times \mathrm{D} 2] \times[\mathrm{D} 13 \times \mathrm{D} 11]$. The cocoon shell percent of the hybrids indicated no signifi- cant difference among them and it ranged from 22.65 to $23.07 \%$ recorded for $[\mathrm{D} 1 \times \mathrm{D} 2] \times[\mathrm{D} 13 \times \mathrm{D} 11]$ and CSR2 $\times$ CSR4 respectively.

\section{Filament length and size}

The filament length of the hybrids showed significant difference $(p<0.01)$ with the longest filament length of 1100 $\mathrm{m}$ recorded in $[\mathrm{D} 7 \times \mathrm{S} 5] \times[\mathrm{D} 13 \times \mathrm{S} 1]$ and the shortest of $970 \mathrm{~m}$ recorded in CSR $2 \times$ CSR 4 with no significant differences in filament size among the hybrids.

\section{Reelability and raw silk}

Reelability and raw silk percent of the hybrids showed significant difference $(\mathrm{p}<0.01)$ with the reelability ranged from 81.48 to $88.00 \%$ and raw silk percent ranged from 16.76 to 18.55 with the highest values for both the parameters recorded for $[\mathrm{D} 7 \times \mathrm{S} 5] \times[\mathrm{D} 13 \times \mathrm{S} 1]$ and the lowest for $[\mathrm{D} 1 \times \mathrm{D} 2] \times[\mathrm{D} 13 \times \mathrm{D} 11]$.

\section{Neatness}

Neatness points of the raw silk indicated the significant difference $(\mathrm{p}<0.01)$ among the hybrids evaluated ranged from 90.67 to 92 with the highest neatness points of 92.00 recorded for $[\mathrm{D} 7 \times \mathrm{S} 5] \times[\mathrm{D} 13 \times \mathrm{S} 1]$.

\section{Cocoon size variability}

Cocoon size variability in the different hybrids studied is presented (Table 3) . It is evident from the data that standard deviation on cocoon indices of the hybrids studied ranged from 6.56 to 11.98 with a minimum value of 6.56 observed for CSR2 $\times$ CSR4. Co-efficient of variation on cocoon indices of the hybrids studied ranged from 4.85 to 7.10 with a minimum value of 4.85 observed for [D7 $\times$ 
Table 3. Cocoon size uniformity in different bivoltine hybrids under large scale in-house testing

\begin{tabular}{ccccc}
\hline Hybrid combination & $\begin{array}{c}\text { Cocoon Length } \\
(\mathrm{cm})\end{array}$ & $\begin{array}{c}\text { Cocoon Width } \\
(\mathrm{cm})\end{array}$ & $\begin{array}{c}\text { Cocoon Index } \\
\left.\left(\mathrm{L}^{1)} / \mathrm{W}^{2}\right) \times 100\right)\end{array}$ & C.V \\
\hline$[\mathrm{D} 2 \times \mathrm{S} 8] \times[\mathrm{S} 1 \times \mathrm{D} 15]$ & $3.44 \pm 0.15$ & $2.05 \pm 0.17$ & $168.88 \pm 11.98$ & 7.10 \\
\hline$[\mathrm{D} 1 \times \mathrm{D} 2] \times[\mathrm{D} 13 \times \mathrm{D} 11]$ & $3.28 \pm 0.19$ & $1.94 \pm 0.14$ & $169.82 \pm 10.86$ & 6.40 \\
\hline$[\mathrm{D} 7 \times \mathrm{S} 5] \times[\mathrm{D} 13 \times \mathrm{S} 1]$ & $3.46 \pm 0.18$ & $2.06 \pm 0.10$ & $168.11 \pm 07.06$ & 4.85 \\
\hline$[\mathrm{CSR} 2 \times \mathrm{CSR} 27] \times[\mathrm{CSR} 6 \times \mathrm{CSR} 26]$ & $3.36 \pm 0.18$ & $1.96 \pm 0.12$ & $171.64 \pm 07.90$ & 6.31 \\
\hline $\mathrm{CSR} 2 \times \mathrm{CSR} 4$ & $3.46 \pm 0.20$ & $2.07 \pm 0.13$ & $166.95 \pm 06.56$ & 5.13 \\
\hline 1) Cocoon length; & & & &
\end{tabular}

S5 $] \times[$ D13 $\times$ S1 $]$. Cocoons of $[D 7 \times$ S5 $] \times[D 13 \times$ S1 $]$ exhibited standard deviation of 7.06 with coefficient variation of 4.85 .

\section{Discussion}

Introduction of the productive bivoltine hybrids had resulted in a linear improvement of cocoon yield and quality of raw silk. However, these productive hybrids could make much impact only to the progressive farmers who could able to provide required input and managerial skills, which were essential to realize the maximum, potential of these hybrids. But whenever, there is an improvement in quantitative characters in parental breeds, the fecundity and survivals are affected significantly. Although, the survival is comparatively more than the parents in single hybrids, the egg number remains low. The fecundity can be increased if the mother moth is a hybrid and it is possible only in case of double hybrids where maximum heterosis in fecundity is observed (Mal Reddy et al., 2003) . Further rearing of foundation crosses, as a seed crop is easy because of their hybrid vigor besides, higher egg recovery in the foundation crosses (Pallavi et al., 2003). In the present investigation, comparative study on the rearing and reeling traits of double hybrid with single hybrid CSR2 $\times$ CSR 4 were made. It was observed that, all the double hybrids recorded a significantly higher fecundity indicating an improvement of $20-24 \%$ over the single hybrid and the results are in conformity with the earlier findings (Mal Reddy et al., 2003). Double hybrid rearing is popularized due to its easy rearing, superiority to parents in growth, vigour, besides higher egg number than that of the single hybrid (Nirmal Kumar et al., 1998) .Egg recovery in the double hybrid is significantly higher in double hybrid than that of the single hybrid (Mahalingappa et al., 2003). Higher survival, a measure of robustness coupled with higher cocoon weight, shell weight and shell percent recorded in the new hybrid, $[\mathrm{D} 7 \times \mathrm{S} 5] \times$
$[\mathrm{D} 13 \times \mathrm{S} 1]$ confers its superiority with regard to tolerance against adverse conditions and consistency in the expression of productivity traits. Evaluation of the double hybrids reported that they are stable in the performance with an average yield of more than $60 \mathrm{~kg}$ per $100 \mathrm{dfls}$ (Joge et al., 2003). Conversion of leaf to cocoon is good in $[\mathrm{D} 7 \times \mathrm{S} 5] \times[\mathrm{D} 13 \times \mathrm{S} 1]$ as evidenced by lower LCR. Cocoon filament length is one of the important economic traits and is considered to have direct bearing on the merit of the hybrid. $[\mathrm{D} 7 \times \mathrm{S} 5] \times[\mathrm{D} 13 \times \mathrm{S} 1]$ recorded significantly higher filament length among the hybrids tested. Higher values recorded for raw silk percent are due to the recombinant genetic vigor of the breeds utilized in the hybrid preparation.

The less cocoon size variability observed in [D7 $\times$ S5] $\times$ [D13 $\times \mathrm{S} 1]$ is due to more uniformity of cocoons shape and size compared to other double hybrids evaluated. Uniform cocoon shape and size are important for getting the quality yarn. To obtain uniform filament size especially in auto and semi-automatic reeling machine cocoon size uniformity is very important (Mano, 1994). Cocoon size variability was found less in the new hybrid [D7 $\times$ S5] $\times[$ D13 $\times \mathrm{S} 1]$ as indicated by standard deviation for cocoon index, which is within the admissible limit $(\leq 8.00)$ with a minimum Co-efficient of Variation. From the present study, it is clear that the performance of the double hybrid [D7 $\times$ $\mathrm{S} 5] \times[\mathrm{D} 13 \times \mathrm{S} 1]$ is better than that of the existing single hybrid in respect of most of the economic traits. Therefore in order to exploit the advantages of bivoltine double hybrids and inherent genetic potential of bivoltines in producing quality raw silk, $[\mathrm{D} 7 \times \mathrm{S} 5] \times[\mathrm{D} 13 \times \mathrm{S} 1]$ can be taken up effectively for further systematic evaluation and commercialization in the field.

\section{References}

Basavaraja HK, Nirmal Kumar S, Suresh Kumar N, Mal Reddy N, Kshama Giridhar, Ahsan MM, Datta RK (1995) 
New productive bivoltine hybrids. Indian Silk 34, 5-9.

Dayananda (2010) Studies on the performance and economic appraisal of new hybrids of the silkworm Bombyx mori L. through validation and demonstration. Ph. D Thesis, Mysore University, Mysore, India.

Joge PG, Pallavi SN, Noseema Begum A, Mahalingappa KC, Mallikarjuna, Dandin SB (2003) Evaluation of double hybrids of silkworm Bombyx mori L. in the field; in Advances in Tropical sericulture. Dandin SB, Mishra RK, Gupta VP, Reddy YS (eds), pp. 102-104, NASSI, Bangalore.

Krishnaswamy S (1990) what ails our bivoltine silk production Programme? Indian Silk 29 (1), 6-14.

Mahalingappa KC, Pallavi SN, Naseema Begum A, Joge PG, Malikarjuna, Sabitha N (2003) Studies on egg yield in double hybrids of bivoltine silkworm Bombyx mori L.; in Advances in Tropical sericulture. Dandin SB, Mishra RK, Gupta VP, Reddy YS (eds), pp. 93-95, NASSI, Bangalore.

Mal Reddy N, Basavaraja HK, Suresh Kumar N, Nirmal Kumar S, Kalpana GV (2003) Breeding of Bivoltine double hybrid $($ CSR6 $\times$ CSR26) $\times($ CSR2 $\times$ CSR27) of Silkworm, Bombyx mori L. for commercial exploitation; in Advances in Tropical sericulture. Dandin SB, Mishra RK, Gupta VP, Reddy YS (eds), pp. 58-62, NASSI, Bangalore.

Mano Y (1994) Comprehensive report on silkworm breeding.
Central Silk Board, Bangalore, India, p.180.

Mano Y, Nirmal Kumar S, Basavaraja HK, Mal Reddy N, Datta RK (1994) A new method to select promising silkworm breeds/ combinations. Indian Silk 31, 53.

Nagaraju J, Raje Urs, Datta RK (1996) Cross breeding and heterosis in Silkworm, Bombyx mori L. Sericologia 36, 1-26.

Nirmal Kumar S, Ramesh Babu M, Basavaraja HK, Mal Reddy N, Datta RK (1998) Double hybrids for improved silk production in Silkworm Bombyx mori L.; in Silkworm Breeding. Sreerama Reddy G (ed), pp. 209-217, Oxford and IBH Publication, New Delhi, India.

Pallavi SN, Naseema Begum A, Ashwath SK, Mahalingappa KC, Joge PG (2003) Evaluation of single parents and foundation crosses of bivoltine silkworm Bombyx mori L.; in Advances in Tropical sericulture. Dandin SB, Mishra RK, Gupta VP, Reddy YS (eds), p. 27, NASSI, Bangalore.

Singh RK, Chaudhury BD (1977) Biometrical methodsn in quantitative genetic analysis. Kalyani Publications, New Delhi, India

Suresh Kumar N, Basavaraja HK, Kalpana GV, Joge PG, Mal Reddy N, Nanjegowda B, Dandin SB (2010) Development of sustainable bivoltine double hybrid of the silkworm, Bombyx mori L. for tropics. Indian J Seric 49, 76-80. 